\title{
Sócrates y los presocráticos, desde Ignacio Ellacuría
}

\author{
Josté. Mora Galiana
}

\section{Observación de la naturaleza:}

\section{Experiencia y realidad}

En 1955 Ellacuría impartió, en el Seminario San José de la Montaña de San Salvador, dos cursos sobre los orígenes de la Filosofía, centrados en Grecia, y más concretamente en los presocráticos: de Tales a Parménides y de Empédocles a Demócrito. Considera Ellacuría en estos cursos que, en el desarrollo de la cultura, el espíritu humano logra su primera madurez del modo siguiente:

- Busca expresar primero las vivencias que le invaden, creando el mundo maravilloso del arte.

- Siente después, frente al entorno que le amenaza, un aliciente de razones, a modo de necesidad técnica para satisfacer su afán de dominio y seguridad: se interna entonces en el ámbito de la ciencia.

- Finalmente, al indagar el enigma de las cosas desde la experiencia, la inquietud intelectual trata de descubrir la explicación de la realidad, alcanzando el punto del filosofar.

Ese es, según Ellacuría, el triple estadio esquemático que se da históricamente en el mundo helénico y que se da - en cuanto a su jerarquía - en el proceso cultural'.

Sócrates y los presocráticos, desde Ignacio Ellacurio 
Al igual que Aristóteles, considera Ellacuría el surgimiento de la Filosofía como un momento en el devenir histórico de la cultura griega, al intentar dar razón del mundo y ensayar su explicación global. Y, en consecuencia, se pregunta sobre qué fue lo que históricamente movió a filosofar a los presocráticos en Grecia, tratando de internarse en la historicidad, al menos condicionante, de la vida de los filósofos y de su filosofía como resultado de un filosofar personal.

Sobre Tales (582-546 a. C.), avanza tres supuestos acerca de la motivación del filosofar, arriesgándose a favor del tercero:

- La pura embriaguez del saber.

- El aprovechamiento de la ciencia en beneficio propio.

- El filosofar, a partir de una situación científica -era astrónomo de oficio-, en busca de una visión unitaria que, desde un único principio, explicase el desarrollo de todos los seres.

Ignacio Ellacuría hubo de tener presente la referencia obligada de la leyenda trasmitida por Platón en el Teeteto, en aquel simbólico cuadro en que se nos presenta al filósofo caído en un pozo por ir absorto en la contemplación del cielo. El texto dice lo siguiente:

“... como Tales, oh Apolodoro, mientras observaba los astros y miraba hacia arriba, se cayó en un pozo, una guapa y graciosa criada se reía de él; se dice que deseaba contemplar las cosas del cielo, pero olvidaba las que tenía delante"?.

Se señala, es cierto, la común percepción del sabio distraído (absorto en sus ideas universales) pero ni se enfatiza la importancia de la constante actitud de la observación, propia de Tales, ni la inquietud intelectual por alcanzar una visión unitaria.

Importa, pues, subrayar en Tales la observación directa de las cosas, basada en la experiencia, lo que dio lugar a la formulación de la hipótesis del agua como elemento primordial. Dicha hipótesis está fundamentada a su vez en la observación de que el alimento de todas las cosas es húmedo y por ello las semillas de todas las cosas tienen una naturaleza húmeda. La diferencia con las cosmogonías de la época sobre el agua, como fuente de todo lo que nace, reside precisamente en la observación y en el intento de formulación racional. 
En Anaximandro, que a la muerte de Tales tenía unos 40 años, aunque el filosofar siguicra entremezclado con expresiones mitológicas, vuelve a repetirse y acrecentarse, según Ellacuría, la necesidad de una concepción general y unitaria del universo, llevada a la ejecución con superior sutileza y con un más alto poder de abstracción. La madurez intelectual alcanzada exige un conocimiento racional del mundo.

Preguntarse por lo que las cosas esencialmente son supone la puesta en marcha definitiva de la Filosofía. Hay una distinción fundamental en donde aparece la virtualidad filosófica de estos primeros pensadores: es la distinción entre naturaleza y cosas, junto con el no fiarse, sin más, de las apariencias. De Anaximandro, también oriundo de Mileto y casi coetáneo de Tales, parte la idea de indagar algo que no sea ninguna de las cosas y que pueda ser constitutiva de todas ellas. Anaximando considera que lo constitutivo de todas las cosas es el ápeiron ("una cierta naturaleza"), con su doble sentido, según Ellacuría, de in-finito: no determinado y no limitado.

Lo que no era sino prenuncio en Tales, cobra con Anaximandro un sentido formal; hay algo de donde salen y a lo que vuelven las cosas: "la naturaleza", entendida como lo divino como lo que está en todo y es la realidad superior constitutiva de todas las cosas.

En este primer filosofar no utilitarista y en la finalidad del pensador helénico cree descubrir Ellacuría una búsqueda de la verdad para saber y poder dirigir la propia vida. Pero este iluminar el comportamiento de la vida y sus posibilidades de obrar será, sobre todo, una constante en la vida del autor.

Anaximenes, que también alcanzó su madurez intelectual hacia el 546-545 a. C., partió de la observación del aliento del hombre al respirar, frío cuando se contrae y condensa, y caliente cuando se dilata. Sobre esa observación explicó la pluralidad de las cosas y dijo que el "sustrato" y elemento primordial, es decir, el principio de los seres es el aire.

Basándose, pues, en una observación inicial sobre el aire de la respiración, retenido en la boca o expelido, avanzó la generalización de que el calor dilata los cuerpos y el frío los contrae, postulando a continuación una explicación con pretensión universal: el elemento primordial del que se originan las cosas que son, las que han sido y las 
que serán, es el aire infinito (que dilatado o condensado se constituye en patrón de la pluralidad fenoménica).

Tanto Tales como Anaximandro y Anaxímenes tratan de dar, según Ellacuría, con un principio de diferenciación de los seres, pero no atienden a que estas diferenciaciones, si de verdad son reales, tienen que ser intrínsecas y diversificar desde dentro, por su misma presencia constitutiva, los seres distintos. Además, quedaba el gran problema, intimamente relacionado con el anterior, de cómo puede surgir lo determinado de lo indeterminado, lo múltiple de lo uno, lo formado de lo informe ${ }^{3}$ (de algún modo, ya alumbrado en la teoría de Anaxímenes). Tal problema lo suscitarán nítidamente los pitagóricos y colocarán no la materia sino lo formal-matemático, que implica orden y armonía, como principio fundamental por el cual las cosas son lo que son.

Los pitagóricos, dice Ellacuría, al situarse ante la cuestión del mundo presocrático, sobre cuál es el principio de todas las cosas, entienden que ese principio no es lo común, lo indeterminado, la materia, sino lo diferenciado, lo determinado y determinante, la forma, el número. "No parece que desconocieran la parte que en la constitución de los seres tiene su parte material, sino que recalcan como más importante la parte formal: como tal escogen acertadamente algo determinado por sí mismo y que, además, implica orden y armonía. Esto significa que como primer principio, como principio fundamental por el cual las cosas son lo que son, ellos colocan la forma, lo formal, tanto en el orden absoluto como en el determinado de cada individuo. Pero esa forma tiene un excesivo sentido matemático, falto, por consiguiente, de realidad, ya que nunca la fórmula o la ley matemática podrá dar el sentido ontológico del ser, sino tan sólo su trazo, su delimitación externa. Ellos percibieron bien la armonía y el orden universal, en los que reconocieron una ley cósmica formulable en leyes matemáticas a través de sencillas relaciones numéricas. El peligro estriba en confundir la expresión con lo expresado, la realidad con su fórmula. Sin embargo, el haber reconocido el fundamental orden del universo entero, el haber intentado su explicación a partir de un elemento ordenatriz y determinante, el haber proyectado en el mundo de la ciencia el sentido de las leyes matemáticas hacen del esfuerzo filosófico de los pitagóricos una de las piedras miliares en el avance de la cultura y la filosofía"4. 
Sobre la personalidad científica de Pitágoras, aunque legendaria y también vinculada a creencias religiosas (tales como la de la transmigración de las almas), subraya Fernando Cubells que los pitagóricos liberaron a la aritmética de la finalidad exclusivamente práctica y que Pitágoras fue el primero en ocuparse de los matémata y de los números, considerándolos como elementos o principios de las cosas ${ }^{5}$.

Tal como lo indicara Aristóteles en el libro I, cap. quinto de la Metafísica: "los denominados pitagóricos, dedicándose los primeros a las matemáticas, las hicieron avanzar, y nutriéndose de ellas, dieron en considerar que sus principios son principios de todas las cosas que son..."'. A su modo, se preguntaron sobre la causa formal, esencia o entidad de las cosas.

En realidad, el descubrimiento de que en todas las cosas existe una regularidad numérica o matemática debió impresionar de tal modo en el pensamiento que produjo un cambio de perspectiva en el desarrollo de la filosofía occidental. Igualmente decisivo fue el descubrimiento de que los sonidos y la música pueden traducirse en magnitudes numéricas ${ }^{7}$

Con los pitagóricos se cierra una primera etapa del pensamiento griego que tiene como mérito, según Ellacuría, la introducción de la Filosofía en la cultura occidental, quedando ya colocados los primeros fundamentos, aunque toscos, de la Filosofía como problemática y como ciencia:

- El problema del principio y el verdadero ser de las cosas.

- La unidad y la multiplicidad de los seres

- La explicación por medio de la naturaleza.

- La insinuación de principios materiales y formales como base del ser y de la intelección de la realidad ${ }^{8}$.

Con los pitagóricos, pues, queda abierto todo el sentido de aventura que supone la búsqueda de la verdad, que consiste en conocer las cosas como son, lo que implica descubrir, desvelando y revelando tras las apariencias, el "verdadero" ser.

En definitiva, el esfuerzo intelectual inquisitivo, original y primitivo, conduce, a Heráclito de un lado y a Parménides y a la escuela eleática del otro, a aportaciones de originalidad decisiva para la histo- 
ria posterior. Ambos, Heráclito y Parménides, vuelven a preguntarse cuál sea el verdadero principio de la realidad. Delimitar la precisa relación entre el ser de las cosas y el ser de la naturaleza es el blanco al que se orienta la actitud inquisitiva de Heráclito y Parménides. La Naturaleza se convierte en principio de que las cosas sean.

Esta implicación entre naturaleza y ser, entre "physis" y “eînai”, es, según $\mathrm{X}$, el descubrimiento casi sobrehumano de Heráclito y Parménides, en los que prácticamente comienza la Filosofía?.

Heráclito (que debió nacer hacia 540 a. C.), a la pregunta de cuál sea el principio de las cosas, viene a contestar en síntesis, según Ellacuría, que la verdadera realidad de las cosas estriba en su hacerse, que, por lo mismo, es un des-hacerse en un ir siendo, y, por lo mismo, en un dejar de ser; en algo dinámico que por su misma oposición interna encuentra el motor de su movimiento y de su ser. Consecuentemente, su principio fundamental es el devenir, el estarse haciendo y deshaciendo, la síntesis de contrarios entre el ser y el no-ser, ya que el moverse exige esa ruptura entre lo que se es y lo que se va a ser.

En esta actualización intelectual de Heráclito, la historicidad del pensamiento de Ellacuría se proyecta hacia el horizonte de la Filosofía de la Liberación, sobrepasando los límites de la mera observación de la naturaleza, horizonte intelectual de los presocráticos.

En efecto, comentando a Heráclito dice Ellacuría: "La verdadera realidad de las cosas..., las esencias de las cosas fluyen, consisten en ese mismo fluir, en oponerse y guerrear dentro de sí, en romper la identidad, consigo mismo: nadie podrá bañarse en el mismo río dos veces, porque ni el río ni el que se bañó pueden seguir siendo quienes eran. La permanencia de las cosas no es sino aparente y, por tanto, falsa e incierta: no puede consistir en ella la auténtica realidad... Las cosas llegan a ser porque devienen hacia un ser que nunca puede ser definitivo o estático y que, por tanto, encerrará en sí mismo el impulso hacia una nueva forma de ser en un proceso inacabable" ${ }^{10}$.

En la filosofía de Heráclito enlaza Ellacuría con el pensamiento dialéctico de Hegel, para quien es una gran conciencia la que se adquiere al comprender que el ser y el no ser son, simplemente, abstracciones carentes de verdad y que lo primordial verdadero está solamente en el devenir". 
Puesto que lo primordial verdadero está en el devenir, Hegel, al estudiar a Heráclito, en la Filosofía de la Naturaleza subraya de éste el "devenir" (principio lógico) y el concepto "tiempo" (primera esencia sensible o intuición abstracta del proceso), así como la determinación física del fuego, "metamorfoseador de las cosas corporales", y lo más incorpóreo de la transformación o evaporación, el alma, que siempre fluye. Pero incorpora la dimensión subjetiva del microcosmos del ser humano, que es conciencia (participación en el "logos" divino en Heráclito), capaz de pensar lo absoluto como la unidad de lo contrapuesto y como proceso de esta diáléctica.

Heráclito es, pues, en definitiva la referencia filosófica primera del devenir histórico, para Hegel, así como de la historicidad y de la transformación histórica, para Ellacuría. El devenir, en consecuencia, es la nota esencial de lo real. La esencia de la naturaleza, primer principio de todo ser, es el devenir.

Hecha esta afirmación de que el devenir es la esencia de la naturale$\mathrm{za}$, resta investigar la realidad concreta cuya esencia manifiesta sea la mutabilidad. Investigación en la que Ellacuría se apoya en Zubiri y se pregunta:

¿Cuál de los seres concretos tiene esas características atribuidas a la naturaleza en permanente devenir? El fuego. El fuego, en efecto, tiene en sí esa lucha de contrarios específica del devenir. Pues el fuego es la concreción de que la verdad no es sino la unidad de lo contrapuesto y que todo en cuanto tal es devenir, conforme a la propia observación empírica de que lo frío se calienta, lo caliente se enfría, lo húmedo se seca, y lo seco se humedece. El fuego "no es la unidad dialéctica del ser y del no ser, sino la unidad cósmica de la generación y destrucción en una única fuerza natural". Para Heráclito ser equivale a "haber llegado a ser"'?

Parménides debió nacer hacia 540 a. C., esto es, hacia la época de la fundación de Elea, en la Magna Grecia, hacia la 69 Olimpíada. Y es probable que conociera el pensamiento de su coetáneo Heráclito, pues considera "errantes" y de "pensamiento vacilante" a aquellos para los que el ser y el no ser son considerados lo mismo y no lo mismo.

Según Ellacuría Parménides, ante la pregunta icuál es la auténtica esencia de la realidad?, se abre a un mundo totalmente distinto: el

Sócrates y los presocráticos, desde Ignacio Ellacuria 
mundo del ser; pues nada es fuera del ser y el propio pensar es ser. Al contemplar a la Naturaleza como realidad o principio activo que proporciona a todas las cosas un elemento común que es el estar siendo, Heráclito lo identifica como devenir y Parménides como ser que es y lo es todo al mismo tiempo, ingénito e imperecedero, inmóvil y sin fin.

"El hallazgo del ser como nota fundamental de la realidad, un ser concebido como plenamente idéntico consigo mismo, ha podido seguir este itinerario: por naturaleza se entiende el principio originario y común del que proceden todas las cosas; ahora bien, el elemento común a todas las cosas y el más radical de todas ellas es el ser; luego es el ser con todas sus propiedades esenciales - fijeza, inmutabilidad, etc.- la forma real y esencial de la naturaleza. "No ha sido ni será sino que es, y lo es todo a un tiempo": he ahí el ser sin historia, el ser negando toda mutabilidad en la antípoda del devenir heracliteo, instalado como la misma esencia fundamental de la realidad. Parménides se atendrá siempre a su intuición primitiva y fundamental, según la cual el ser se presentará siempre como algo inmutable, a la vez que la inmutabilidad se ofrecerá como condición indispensable del ser: no puede estimar como ser sino lo que no puede ser de otro modo, lo que por siempre es. Idea esta última que se entrañará en el núcleo mismo del platonismo y, purificada, en el de la filosofía perenne"13.

La aportación principal de Parménides ha sido aproximarse al "ser", y situarlo como objeto central de toda discusión metafísica. Pero la visión esférica del ser de Parménides, correlato real y sensible de la naturaleza perfecta, con independencia de que pueda ser corregida desde otra comprensión, planteamientos o perspectivas distintas, no puede separarse del método o camino emprendido, camino de lo razonable que lleva a conocer todas las cosas, en el mundo de las apariencias o de lo sensible, hasta llegar a la "verdad bien redonda", el real ser de las cosas en expresión de Ellacuría lo que plantea definitivamente el problema del método en la Filosofía.

En el estudio del Proemio de Parménides (en el que los caballos llevan al filósofo tan lejos como es su deseo al camino razonable de la diosa), considera Fernando Cubells que, en su primera mitad, se fundamenta la actividad filosófica, exponiendo su razón, medios y objetivos: "En primer lugar se destaca la contraposición entre el mundo 
sensible (morada de la noche, mundo del que el poeta se aleja) y el mundo ideal (la luz). Con la imagen del viaje se describe el quehacer filosófico como tendencia a situarse en el segundo. Y finalmente, se exponen los medios con que para ello cuenta: el método (el camino), la apetencia del mundo ideal que le impulsa hacia él (los caballos) y el principio que determina e informa esta apetencia, el presentimiento cada vez más claro de su objeto (las Helíades)"'+4.

Aunque E no entra en el estudio pormenorizado del proemio de Parménides, conviene salvar mínimamente esta carencia por el valor que tiene a la hora de destacar y subrayar algunos elementos estilísticos y las implicaciones de su significado.

En efecto, en estrecha relación con el camino o método a seguir están los caballos, que aportan su fuerza y son los que tiran del carro, y las Helíades que guían, indicando rectamente la dirección del camino y "desvelando" en el viaje, en una progresiva iluminación ("quitándose con la mano los velos de la cabeza") el lugar que separa la noche y el día:

ข. 10

"Alli está la puerta de los caminos de la noche y el dia", la circunda un dintel y un umbral de piedra. Etérea está obstruida por grandes batientes de los que Diké, severa castigadora, guarda las llaves de la Irecompensa,

a la cual las persuasivas doncellas con suaves palabras convencen hábilmente para que el pasador asegurado con estacas les retire pronto de la puerta; ésta de los batientes dejó la inmensa abertura, subiendo a lo alto, haciendo girar alternativamente en los cubos sus dos ejes de [bronce provistos de traviesas y pasadores. Por alli, a través de ella, las doncellas condujeron rectamente por el camino el carro y los [caballos,

y la diosa me recibió bondadosamente, con su mano mi mano derecha tomó y dirigiéndose a mi, habló de esta forma: "Ob joven, compañero de aurigas inmortales que llegas a nuestra morada con los corceles que te llevan, iSalve!. Pues no te ha impulsado una mala Moira a seguir

Sócrates y los presocráticos, desde Ignacio Ellacurio 
este camino (que esta lejos de la senda que siguen los hombres) sino Themis y Diké. Es necesario que conozcas todas las cosas,

el corazón inconmovible de la Verdad bien redonda y las opiniones de los mortales en las que no está la verdadera certeza. Pero deberás aprender también esto: que lo que aparece debe tenerlo por real quien lo recorra todo absolutamente"'s

En el verso 14 aparece el nuevo personaje y concepto Diké, que tiene una doble significación en la literatura griega: justicia y lo que es justo, en sentido ético y jurídico, pero que también se emplea en el sentido de ajustado a una norma en general o a la misma naturaleza de las cosas.

Diké recompensa alternativamente con premio o castigo abriendo o cerrando la puerta. Esta puerta es un lugar decisivo, es el límite entre los caminos de la noche y el día. Decidirse a emprender el camino de la sabiduría que queda lejos de la senda que siguen los hombres no obedece a ningún impulso negativo o fatal sino el deseo ("eros" platónico) de ajustarse a la exigencia de lo recto y verdadero. A Dike, por tanto, se debe que el sabio pueda llegar a la luz, término de su viaje.

En el verso 24 comienzan las palabras de la diosa, discurso por el que, tras la salutación, se revela la verdad al sabio viajero. En el saludo, además, se recapitula lo anteriormente expuesto:

El sabio es compañero de las Helíades; el camino es poco frecuentado por los hombres. El sabio es impulsado por Themis y Diké, es decir, por la decisión de ajustarse a la verdad. En la decisión interviene la voluntad y la razón. Esa es la condición indispensable para conocer la realidad de todas las cosas y el corazón inconmovible de la Verdad bien redonda: utilizar la vía del Ser, por la que lo ente es ${ }^{16}$.

Pero no debe olvidarse la advertencia final: quien lo recorre todo absolutamente, lo que aparece debe tenerlo por real.

Parménides, al sostener un principio de realidad - la inmutabilidadcontrario al de Heráclito —el devenir-, tenía que concluir por un primer principio opuesto al fuego, como es esa esfera fija e inmutable.

Parménides, afincado en el ser, da entrada a la ontología en cuanto tal que, en Zubiri y Ellacuría, más allá del "constructo" del concepto ser, tendrá que volver hacia la realidad y la realidad histórica en cuanto 
tal. Heráclito, al considerar esencial el devenir, da entrada, por su parte, en el ser de la realidad, al concepto de tiempo e historia, propio de la Filosofía más reciente. Pero uno y otro aportarán, por el camino inductivo Heráclito y por el camino especulativo Parménides, la exigencia de alcanzar la verdad de la realidad.

Considera Ellacuría que Parménides marca un principio de subjetivismo al forzar la inteligibilidad del ser conforme a moldes de pensamiento puramente humano: en él, al contrario de Heráclito, es la mente la que señala la pauta y no la realidad. La exageración posible y factible de tal presupuesto puede considerarse como una de las primeras luces con que alarma el idealismo a las filosofías objetivas ${ }^{17}$.

Pero no debe olvidarse que Parménides tuvo una actividad política, legislando para sus compatriotas, de modo tal que cada año los magistrados hacían jurar a los ciudadanos a obrar según las leyes parmeníadas ${ }^{18}$. El propio Hegel, apoyándose en Diógenes Laercio, hace referencia al prestigio de Parménides como legislador entre sus conciudadanos de Elea, así como a la proverbial vida parmenidiana, vida moralmente ejemplar

Jenófanes (570-475 a.C.), oriundo de Colofón, en la Jonia, tal como indica Hirschberger (a quien sigue Ellacuría en su Historia de la Filosofía), al final de una vida errante se instala en Elea. Predecesor de Parménides, inicia una purificación decisiva del Olimpo griego, fantaseado por Homero y Hesíodo: "los dioses creados a la semejanza de los hombres con el propósito de legitimar las más ruines flaquezas de los hombres no son dioses... Dios es uno solo y sus propiedades sólo se alcanzan pensando lo mejor que pueda pensarse" 19 .

Pero más que el estudio analítico de los textos presocráticos, iniciado por el filólogo alemán Herman Diels (1848-1922), le interesa a Ellacuría el rumbo histórico seguido por el despertar de la Filosofía. En consecuencia, sobre Jenófanes y su pensamiento sobre Dios, se limita a decir que, en el siglo VI a. C., no se alcanzó una distinción acabada entre el mundo y Dios pero que las disquisiciones sobre la divinidad demuestran en Jenófanes un penetrante espíritu filosófico, próximo en sus resultados a la concepción que los israelitas sustentaban sobre la divinidad.

En realidad, Jenófanes critica la concepción antropomórfica que sus contemporáneos tienen sobre los dioses (los mortales, dice, creen 
que los dioses han nacido y que tienen vestido, voz y figura como ellos). Indica que si los caballos, los bueyes y los leones pudieran dibujar, los dibujarían semejantes a sí mismos, al igual que hacen los etíopes o los tracios. Por lo que, frente a la revelación, afirma la búsqueda que con el tiempo descubre lo mejor.

Hay, pues, en Jenófanes una teodicea negativa, acerca del único Dios ("el supremo entre dioses y hombres, ni en figura ni en pensamiento semejante a los mortales"). Pero a la hora de precisar, sobre ese supremo dios entre los muchos dioses griegos y los hombres, lo describe como el que todo ve, el que todo piensa y el que todo escucha.

Zenón (460 a. C.), natural de Elea, el gran discípulo de Parménides, es para Ellacuría, con lo que refrenda a Hegel, el iniciador de la dialéctica. Esta dialéctica aparece bien descrita en el Parménides de Platón, diálogo de las ideas.

En efecto, Parménides muestra que todo es uno; Zenón enseña que lo múltiple no existe. Pero Zenón se afirma en la tesis de Parménides, rebatiendo el pensamiento contrario a éste, para demostrar a quienes predicaban el ser de lo múltiple que lo múltiple no existe, puesto que es imposible que los seres desemejantes sean semejantes y los semejantes sean desemejantes, a menos que exista una forma en sí: el ser, del que participan todas las cosas, al igual que de la forma en sí del hombre participan todos los seres humanos, y lo mismo de la forma en sí del fuego o del agua.

Hay, dice Ellacuría, entre los modos de filosofar intelectualista dos formas fundamentales: una, la del que atiende a las cosas; otra, la que se atiene a las razones de las cosas. A la forma dialéctica de pensar perteneció Zenón. Pues Zenón fue el primer apologista de su maestro Parménides, dialéctico con sus opositores, haciendo valer el argumento de que nada es si lo Uno no es.

Lo que a Ellacuría le interesa subrayar de Zenón es que el haber sido iniciador de la dialéctica y el acaecerle que lo propio y peculiar suyo sea la dialéctica es algo de enorme importancia para la historia de la filosofía. Pues hay, en efecto, entre los modos, llamémoslo así, intelectualistas de filosofar dos formas fundamentales: "una, la del que atiende a las cosas; otra, la que se atiene a las razones de las cosas. Aquélla es siempre la inicial, la propiamente creadora, la que se pone

\section{6}

Realidad 90, 2002 
en inmediato contacto con la realidad a la que trata de arrancar su secreto y su verdad. La otra, la dialéctica, es ya la propia de la escuela, la que anda tejiendo y destejiendo razones más que verdades, distingos y sutilezas $\sin$ inmediato interés por la realidad, antes atento a los argumentos de los adversarios a quienes se pretende acallar. La primera de esas formas de filosofar propende a ser poco pulida y crítica; la segunda tiende a ser poco realista.

A esta segunda forma de filosofar pertenece Zenón con su enorme inteligencia de dialéctico al servicio de la filosofía fundamental que creó Parménides. No es que sea un repetidor, puesto que en orden de las razones es más sutil y variado que su maestro, pero ya no trabaja tanto de cara a la realidad cuanto a la polémica" 20 .

Según Ellacuría, aunque Zenón haya exacerbado la contraposición entre el movimiento y la fijeza del ser, con ingeniosos argumentos, la Filosofía, en Parménides y Heráclito ha sido puesta en marcha de tal modo que, en lo sucesivo, cualquier desarrollo cultural necesitará confluir hacia ella. Pues el quehacer filosófico es un menester histórico que tiene por sujeto y por destino la humanidad entera.

No pasa por alto Ellacuría que estos primeros héroes, y mártires del pensamiento, no sólo murieron a la banalidad y a la apariencia sino que murieron también en el destierro o el suplicio. Tal fue el caso de Zenón, cuya muerte hizo especialmente famosa la fortaleza de su alma frente al tirano que avasallaba la Ciudad-Estado (no se sabe si de Elea o de otra ciudad de Sicilia) ${ }^{21}$.

Existen, tal vez, grandes líneas diversas en el pensamiento filosófico desde la iniciada por los presocráticos, en el horizonte de la naturaleza, desde la observación de las cosas hacia el principio constituyente de su realidad o esencia de las mismas; unas más racionalistas, otras más empiristas; unas más idealistas (en cuanto que eidos designa una realidad formalmente), otras más realistas u objetivas. Ahora bien, lo que parece interesar a Ellacuría, desde el principio del estudio y exposición del pensamiento filosófico, es mostrar cómo evoluciona la historia, cómo es la filosofía históricamente, en su despertar, y contribuir así, de ser posible a "apresurar ciertos amaneceres"22.

Con lo que queda apuntada también la dimensión ético-política del quehacer filosófico antes de entrar en la segunda parte de la exposición de los presocráticos, de Empédocles a Demócrito, que nosotros 
enmarcamos en la indagación de lo real y en la búsqueda de la verdad. Esta dimensión ético-política ya tuvo su importancia en el propio Parménides, como legislador y referente de una vida moral ejemplar.

\section{Admiración e indagación de lo real:}

\section{La búsqueda de la verdad}

Al reflexionar sobre el despertar de la Filosofía, considera Ellacuría que, sea la admiración el inicio de la Filosofía, según platónicos y aristotélicos, sea la angustia de quedarse a la deriva sin suficiente luz y seguridad para orientarse en la vida, según los existencialistas, en ambos casos nos encontramos ante una necesidad vital de profundo carácter intelectual: "necesidad vital porque es todo el hombre quien se siente impelido por una inquietud que le desasosiega y le urge por entero; de carácter intelectual porque trata de formular ideológica y sistemáticamente una concepción del mundo, porque trata de investigar intelectualmente las cosas como son, de tener claro lo que fuera está escondido, lo que a los demás se les ofrece superficial y oscuro"'3.

Conviene recordar que, en el Teeteto, diálogo platónico sobre la Ciencia, ejemplo de la mayeútica, se pone en boca de Sócrates lo siguiente:

“iAh querido Teeteto!, no has lanzado vanas sospechas en la crítica de ti mismo. Muy propio del filósofo es el estado de tu alma: la admiración. Porque la filosofía no conoce otro origen que este..."2t .

Para Sócrates, tal es el estado del alma ante la sensación de un continuo devenir y la razón de que nada es tal como se presenta, lo que le lleva a definir a la Ciencia como "la opinión verdadera acompañada de razón”, desde la admiración y la duda.

Pero conviene señalar también, como lo hace recientemente Manuel Martín Gómez, al hablar de Jenófanes, que la propia admiración lleva a ahondar en el concepto de verdad, certeza e investigación, como una especie de caza o persecución, que se inicia en el tiempo y requiere tiempo y búsqueda persistente hasta alcanzar, en un determinado descubrimiento, parte de verdad, siempre relativa. Pues Jenófanes, "al afirmar que el hombre ni conoce, ni llegará a conocer la verdad sobre 
los dioses, que pertenecen a la misma esfera entitativa que el hombre, extiende la problemática a todo objeto de conocimiento y se adelanta de este modo a la postura de escepticismo y relativismo, que decimos inaugurada por los sofistas más tarde" 25 .

El propio Ellacuría, al estudiar a los presocráticos y facilitar sus apuntes pretende descubrir varias cosas al mismo tiempo:

- Cómo es la primera entrada del hombre en la filosofía, por medio de un contacto desnudo con la realidad.

- Cómo es, hasta cierto punto, la primera entrada de las cosas en la filosofía, al ofrecerse la realidad tal cual a la mente.

- Cuál es la validez y el significado de las ideas abstractas, con independencia de la subjetividad concreta.

- Cuál es la vertiente histórica y concreta de las ideas, resultado del quehacer humano al tener que habérselas con las cosas.

- Qué se pretendió expresar conceptualmente en la visión primigenia, a pesar de la tosquedad primitiva de los presocráticos.

Hay, en consecuencia, hacia la realidad y hacia los propios presocráticos, como quedara patente en los diálogos de Platón, admiración, indagación y búsqueda de la verdad, todos pasos definitivos en los albores de la Filosofía.

Sobre la sima abierta entre el pensamiento de Heráclito y el de Parménides, abierta más - según E- por la visión inicial que por los conceptos que la expresan, los próximos pensadores van a tratar de establecer un puente de conciliación entre la veneración al pasado y la exigencia de una nueva visión del mundo.

Dice Ellacuría: "En toda la filosofía anterior a los conciliadores se daba, ya desde los primeros tiempos de Tales, una dualidad: la de naturaleza, por un lado, y la de cosas por otro, realidad y apariencia, ser y seres, aunque esto último más como intuición oscura que como planteo definitivo. Tal dualidad suscitaba de inmediato dos cuestiones fundamentales: cuál es la verdadera realidad tras las cosas que aparecen, y cómo se posibilita el cambio real desde aquella realidad a estas cosas. Heráclito, proponiendo una realidad fundamental en esencial devenir, estaba aparentemente más a punto para explicar la aparición y la desaparición de las cosas que pasan y que, en una primera superfi- 
cie, se muestran como algo que realmente está pasando; Parménides, en cambio, adscrito hasta sus últimas consecuencias a su concepción de la realidad fundamental como ser fijo, negará la posibilidad del cambio y, consecuentemente, la realidad de las cosas en cuanto tales... Heráclito parecía negar la razón y la metafísica, Parménides la experiencia tal como se nos impone; los conciliadores, con la ventaja de no estar sobrecogidos por el vértigo de los descubrimientos iniciales y personales, juzgan que ninguna de ambas negaciones es legítima"26.

Empédocles, que nació después de Anaxágoras, aunque se le anticipó en su actividad filosófica, como indica Aristóteles (en la Metafísica, libro I, cap. tercero, 984 a 11), es probable que viviera del 495 al 435 a. C. ${ }^{27}$.

El horizonte de Empédocles es el peculiar de la especulación presocrática, circunscrita sustancialmente, según Ellacuría, a lo cosmológico y con permanentes interferencias entre los campos de la física y la metafísica. En efecto, en la búsqueda de un principio inmutable, capaz de explicar el devenir y la pluralidad de lo que se nos muestra, hay una clara interferencia cosmológica al preguntarse el filósofo de qué cosas primordiales están constituidas las cosas derivadas, haciéndose así imposible una metafísica general sobre el ser. "Este no reconocer más que un solo plano de la realidad es lo que obliga, como a casi toda la especulación presocrática, a formular la cuestión de la unidad y la multiplicidad como una cuestión sobre el "origen" real de las muchas cosas a partir de una sola; con el agravante de que, tras las doctrinas de Heráclito y Parménides, se ha introducido ya en el problema una cuña metafísica sobre la verdadera condición de la realidad"'s8.

Empédocles trata de explicar la unidad de este mundo múltiple preguntándose por el origen de todas las cosas naturales a partir de unas pocas. "En esto último percibimos inmediatamente el paso decisivo a que ha obligado el esfuerzo filosófico de la bina HeráclitoParménides, ya que antes de ella el origen de las cosas era una sola: agua, ápeiron, aire, fuego...; en cambio, desde ellos, los presocráticos restantes acudirán a una multiplicidad como origen: cuatro elementos en Empédocles, átomos infinitos en Demócrito, homeomerías en Anaxágoras..." 29 . 
Se reconoce, pues, una multiplicidad real de seres, y no se admite que pueda darse un cambio esencial de "no-ser" a "ser" o de "no-sersustancialmente-así" a "ser-algo-sustancialmente-distinto". Por lo que Empédocles entiende que basta con admitir cuatro elementos o realidades primarias: el aire, el fuego, el agua y la tierra, de las que, por mezcla puramente externa y superficial resultan las demás cosas, combinaciones en grado diverso de los primeros cuatro elementos primigénios, raíces de todas las cosas.

Tal vez conviene, en este punto, avanzar una hipótesis sobre la finalidad de la filosofía presocrática, que es la de articular un proyecto que explicara globalmente la realidad, en el horizonte de la Naturaleza.

"Pero el principio fundamental de la inmutabilidad del ser propugnado por Parménides necesariamente debía llevar a ulteriores consecuencias: era menester, desde luego para evitar toda mutabilidad esencial, atenerse a unos cuantos principios originarios a partir de los cuales, por una simple mezcla, se explicasen todas las otras cosas; pero, además, era preciso buscar "fuera" de esos principios algo que los pusiese en movimiento, sin el cual no podría explicarse aquella mezcla... Los principios de tal movimiento son expresados por Empédocles bajo la forma del Amor y el Odio...".30

Una vez más, Ellacuría, ante las aportaciones de la filosofía presocrática, recurre a Hegel y a Aristóteles para señalar las luces y las deficiencias. Empédocles, de reconocidas dotes poéticas, en su filosofía Sobre la Naturaleza, con resonancias del poema de Parménides, había visto la necesidad de fuerzas exteriores para poner en movimiento las cuatro raíces de las cosas: la fuerza unitiva del amor y la fuerza disgregadora del odio. Pero no se hace una pregunta fundamental: ¿cuál es la naturaleza de esas fuerzas?

Según Hegel, los cuatro elementos de la naturaleza son, para Empédocles, elementos reales, y el amor y el odio son principios ideales ${ }^{31}$.

Según Ellacuría hay en Empédocles incluso un atisbo de evolucionismo:

"En efecto, ... de la Esfera se pasa al Cosmos; van ascendiendo el aire y el fuego para estructurar los cielos, van descendiendo la tierra y el agua para formar la Tierra; sigue la disgregación debido a la discordia, al odio.

Sócrates y los presocráticos, desde lgnacio Ellacurio 
Vuelve a imperar el amor. Empédocles no dice por qué, sino que lo afirma como un hecho necesario, ya que sólo con el odio tendríamos una disgregación absoluta... En este sentido hay una razón deductiva, pero que salta a lo último sin pasar por lo próximo... Y de resultas del imperio del amor, lo semejante se une con lo semejante: primero surgen los árboles que se alimentan de la tierra, después se van unificando las distintas partes de los animales...

Hay, pues, en Empédocles un intento de sistema completo en el que se viene de una metafísica general hasta la consideración del hombre, una consideración poco humana, poco histórica...

Respecto del hombre, Empédocles inicia una psicología del conocimiento. De claro y recto sabor filosófico son aquellas frases:

Por la tierra conocemos la Tierra; por el agua conocemos el Agua; Por el éter conocemos el divino Éter, por el fuego conocemos el devorante [Fuego; Por el amor conocemos el Amor; con discordia conocemos la Discordia

\section{Funesta.}

La explicación concreta será falsa, pero el principio de que lo semejante es conocido por lo semejante no deja de ser profundo y trascendente; y sucede lo mismo con el intento de explicación de la objetividad de nuestro conocimiento sensitivo - a partir de emanacionesque viene de la realidad en busca de su sentido específico que, a su vez, sale en busca de lo que es semejante.

El otro extremo requerido para, en unión con el hombre, explicar las obligaciones éticas de éste es Dios... Difícilmente podía llegar desde sus presupuestos metafísicos a la idea de la divinidad; sin embargo, ésta se hace presente en su obra y en su vida. Esta presencia de la divinidad tiene su origen en influjos órficos religiosos y en la persuasión común que tan brillantemente había introducido Jenófanes en la filosofía...

Aristóteles parece entender que el Dios de Fimpédocles es la Esfera o estados iniciales de los cuatro elementos reunidos y que, por lo tanto, excluye la discordia e incluye en algún modo el amor. De nuevo estariamos en una concepción panteística que confundiría a Dios con 
la Naturaleza de los presocráticos, es decir, aquel principio del que fluyen los demás seres, pero de modo que el principio siga activamente constituyéndolos... Por eso, aunque ya Empédocles rechace una consideración antropomórfica de la divinidad, sigue enfocándola bajo un panteísmo materialista, que patentiza cuán basto era aún su pensamiento filosófico" "3?.

De todos modos conviene tener en cuenta que el deslinde de los tres saberes vigentes en tiempos de los presocráticos: el teológico, el matemático-geométrico, y el de la fisis, era bastante precario. El Uno, que se expresa por la figura de la esfera, como "Verdad bien redonda" de Parménides, es un modo de significar la vida en sí misma, la infinitud y lo eterno, ámbito distinto del movimiento y mutación real de las cosas, pues uno es el ámbito de lo físico, otro el ámbito de lo formal (ya sea matemático, geométrico o puramente especulativo), y otro el ámbito de lo mistérico, órfico o teológico.

En el caso de Empédocles, la tradición, además de un gran número de fragmentos del poema De la Naturaleza (cosmológico y esotérico), nos ha legado también las Purificaciones (de tipo religioso y antropológico). Su ética no se deduce de su metafísica, sino que es una acomodación de elementos órfico-pitagóricos, interpretados a la luz del Amor y la Discordia.

En efecto, según Ellacuría se da en Empédocles la concepción de una preexistencia de las almas - de forma oscura y confusa- , una caída de las almas a este mundo, una purificación por sucesivas transmigraciones y una vuelta a un estado primitivo feliz, cuya esencia no se ahonda. De esta concepción se deducen ciertos preceptos morales que intentan facilitar la purificación y la liberación definitivas, a cuya luz se justifican; el pecado y la falta son estimados como tales más por la íntima y general persuasión de que son tales, que por un razonamiento ${ }^{33}$.

Queda también en la tradición la especial personalidad de Empédocles, de perfiles legendarios ("domador de los vientos") y de cierto signo de realeza, dadivoso con ciudadanas indigentes; médico, taumaturgo y orador, además de filósofo.

Anaxágoras (500-428 a. C.) era de Clazómenas. Comenzó a estudiar filosofía en Atenas a los veinte años. Su problema fundamental, a pesar de su genialidad y sus divergencias con Empédocles, es similar al 
de éste: hay que admitir, con Parménides, la inmutabilidad del ser; pero, fiándonos de los sentidos, hay que admitir también la pluralidad de los seres. ¿Cómo conciliar ambos extremos?

La conciliación anterior de Empédocles entre la multiplicidad de seres y la unidad del ser se había resuelto combinando cuatro elementos primigenios puestos en movimiento por dos fuerzas: la unitiva, del amor, y la disgregadora, del odio. Se había vislumbrado, pues, la posibilidad de que la naturaleza, la realidad radical, fuera un principio múltiple.

Anaxágoras se persuade de que la gran diversidad con que se nos presenta el mundo no puede surgir de cuatro elementos. Sustituye los cuatro elementos (agua, tierra, éter y fuego) por multitud de elementos, simientes y constitutivos de las cosas, que denominó "spérmata" (semillas) y "khrémata" (cosas), lo que Aristóteles denomina "homeomerías" ${ }^{3+}$.

Se plantean con las aportaciones de Anaxágoras dos cuestiones: cómo y por qué se juntan los elementos hasta formar cosas determinadas; y quien imprime el movimiento necesario para que se junten tan determinada y ordenadamente.

Ambas preguntas y problemas se solucionan en el hallazgo del Nous, de la mente, del espíritu que trata de explicar honda y metafísicamente no sólo el movimiento, sino su razón, su origen.

Anaxágoras, según Ellacuría, intuyó la entidad del espíritu como independencia intrínseca de toda materia, pero no fue consecuente con esa intuición fundamental cayendo, por lo menos, en expresiones que la confunden entitativamente con la materia, a pesar de que en el comportamiento que le atribuye ya anuncia una forma de ser estrictamente espiritual. Además, su hallazgo del Nous le lleva a una purificación sustancial del concepto de divinidad, aun sobre los logros ya obtenidos por Jenófanes ${ }^{35}$.

Es claro que, en Anaxágoras, no se alcanza todavía el concepto de causalidad final, con lo que no se acaba de percibir la trascendencia metafísica racional y última del Nous, en la ordenación del mundo. Pero la crítica que Platón pone en boca de Sócrates en el Fedón le parece excesiva a Ellacuría por cuanto que "consiste en exigirle al que sostuvo la inteligibilidad y el ordenamiento del mundo que explique con su mente necesariamente limitada las finalidades concretas de se- 
res que son necesarios en cuanto carecen de libertad, pero cuya actuación y finalidad no puede ser formulada a priori por cuanto admite diversas posibilidades independientes de su esencia - al menos en parte-, por lo que se refiere a su actuación y aun a los fines concretos" 36 .

Dice Sócrates: "Estoy lejos de creer... que conocozco la causa de ninguna de estas cosas, pues me resisto a admitir siquiera que cuando se agrega una unidad a una unidad, sea la unidad a la que se ha añadido la otra la que se ha convertido en dos, o que sea la unidad añadida, o bien que sean la agregada y aquella a la que se le agregó la otra las que se conviertan en dos por la adición de la una a la otra... Y una vez oí decir a alguien mientras leía un libro, de Anaxágoras, según dijo, que es la mente la que pone en orden y la causa de todas las cosas. Regocijéme con esta causa y me pareció que, en cierto modo, era una ventaja que fuera la mente la causa de todas las cosas. Pensé que, si eso era así, la mente ordenadora ordenaría y colocaría todas y cada una de las cosas allí donde mejor estuvieran... Haciéndome, pues, con deleite estos cálculos, pensé que había encontrado en Anaxágoras a un maestro de la causa de los seres de acuerdo con mi deseo, y que primero me haría conocer si la Tierra es llana o esférica... Mas mi maravillosa esperanza... la abandoné una vez que, avanzando en la lectura, vi que mi hombre no usaba para nada de la mente, ni le imputaba ninguna causa en lo referente a la ordenación de las cosas, sino que las causas las asigna al aire, al éter, y a otras muchas cosas extrañas. Me pareció que le ocurría algo sumamente parecido a alguien que dijera que Sócrates todo lo que hace lo hace con la mente, y acto seguido, al intentar enumerar las causas de cada uno de los actos que realizo, dijera en primer lugar que estoy aquí sentado porque mi cuerpo se compone de huesos y tendones... Pero si alguno dijera que sin tener tales cosas, huesos, tendones, y todo lo demás que tengo, no sería capaz de llevar a la práctica me decisión, diría la verdad. Sin embargo, el decir que por ellas hago lo que hago, y eso obrando con la mente, en vez de decir que es por la elección de lo mejor, podría ser una grande y grave ligereza de expresión. Pues, en efecto, lo es el no ser capaz de distinguir que una cosa es la causa real de algo y otra aquella sin lo cual la causa nunca podría ser causa... ${ }^{37}$

Revela esta crítica platónica, propia del racionalismo griego, de una visión excesivamente antropocéntrica. Tuvieran razón Sócrates y Platón

\section{5}

Sócrates v los presocráticos. desde lanacio Ellacuria 
si Anaxágoras hubiera identificado el Nous con la mente de cada hombre, pero tal presupuesto no aparece en el pensamiento de Anaxágoras. Revela, además, que la filosofía ha cambiado de signo en su época, convirtiéndose de especulación sobre el mundo en reflexión sobre el hombre. Pero, a lo más, en el pensamiento de Anaxágoras, la mente humana no pasa de ser una participación del Nous que no agota sus medidas.

Concluyendo su estudio sobre Anaxágoras, dice Ellacuría: "Lo que el filósofo de Clazomene ha traído a la filosofía perenne es, pues, de un valor extraordinario, más desde luego, por el capítulo del Nous que por el de las homeomerías, aunque también por éste, como veremos en Demócrito". Admiró Ellacuría, en este, autor el equilibrio entre su personalidad metafísica y su personalidad científica, equilibrio presidido por el sentido de contención para no llevar su hallazgo hasta extremos que desbordan la inteligencia humana. Por lo que, concluye, "debe atribuírsele una suprema elegancia intelectual hecha de intuición profunda, poder arquitectónico, vigor sintético y comedimiento equilibrado, que le condujeron a esa solución finalística tan universal y, al mismo tiempo, tan moderada" 38

Demócrito (460-370 a. C), llega a la filosofía con una preparación científica pero impulsado por el afán de encontrar una visión orgánica y última del mundo, lo que fuerza a conciliar la inmutabilidad del ser con la pluralidad y la movilidad de las cosas.

Su discurso y su actitud anuncian ya al pensador de corte experimental-sensualista sin más horizonte que las cosas fijas, experimentadas por él y presupuestas implícitamente como las únicas existentes. Sus proposiciones se reducen a tres, por lo que toca a la explicación de lo múltiple a partir de lo uno:

Existe el ser en forma de una multitud infinita de átomos sin más determinación y diferenciación que su figura, magnitud, peso y situación.

a) Existe el no-ser o vacío, pues sin su presencia es imposible el movimiento que, a su vez, es necesario para explicar la pluralidad actual de las cosas.

b) Existe el movimiento necesario, que no ha venido a los átomos desde fuera, sino que es una propiedad esencial e intrínseca que les es propia. 
Con tales consideraciones parece que se explica el mundo, y en realidad se explica dentro del campo no último, propio de las "ciencias"; se atiende, pues, a lo experimentable, a lo palpable y de ello no se pregunta sino por sus constitutivos que agotan el todo en cuanto a su concreción material. Pero la experiencia intelectual se enfrenta con otras realidades, cuya razón de ser no estriba en los constitutivos materiales de las cosas como observara Platón por boca de Sócrates:

"Que se diga que si no tuviera huesos ni músculos y otras cosas parecidas, no podría hacer lo que juzgara a propósito, pase; pero decir que estos huesos y estos músculos son la causa de lo que hago, y no la elección de lo que es mejor, sirviéndome para ello de mi inteligencia, es el mayor de los absurdos" ${ }^{39}$.

Conviene señalar además que, el propio Aristóteles subrayaba el punto más conflictivo del pensamiento de Leucipo y su compañero Demócrito, respecto de las causas en la Filosofía Preplatónica, en la Metafísica, libro I, capítulo IV, en los siguientes términos:

"Leucipo y su compañero Demócrito sostuvieron que los elementos son lo lleno y lo vacío, a los cuales llamaron ser y no ser respectivamente..., como el vacío existe no menos que el cuerpo, se sigue que el no ser existe no menos que el ser. Juntos los dos, constituyen las causas de los seres materiales" $\$ 0$.

Entendemos, pues, a Demócrito, dice E: “apreciamos la racionalidad de su exposición dentro del estrecho margen experimentalista y no último que ha elegido para sus investigaciones; por eso, comprendemos también su fallo fundamental, que consiste en cierta forma de positivismo, según la cual se confunde la filosofía con cualquier clase de ciencia, con lo que, simplemente, se niega la filosofía... En él,... el hábito científico y experimentalista lo hizo sumamente perspicaz para lo próximo y parcial, pero le obstaculizó el paso a lo último, a lo total, a lo formal y teleológico.

Como parte de todo este mundo, ... el vacío y el movimiento se encuentran en esa cosa singular que llamamos hombre. Demócrito, como nuestros modernos científicos materialistas, no aprecia en él ninguna diferencia sustancial respecto de las demás cosas; disgregado el hombre, no encontraríamos en él más que un conjunto de átomos que cualitativamente no difieren de aquellos en que se disgregarian los demás objetos"+1.

\section{7}

Sócrates y los presocráticos, desde Ignacio Ellacurio 
Aun reconociendo la aportación de Demócrito al futuro de las Ciencias geológica y biológica, para Ellacuría este positivismo, no obstante, al no separar entre materia y vida, obceca la mirada metafísica y achata los horizontes mentales. Con los presupuestos estrictamente materialistas, carece de sentido hablar, en la sociedad humana, de aspectos éticos y teológicos. Con todo, Demócrito asienta como norma de moralidad hedonista el agrado, constituyendo el placer y el dolor el criterio de lo útil y lo perjudicial, sin caer en el hedonismo o materialismo grosero, toda vez que defiende como necesario el dominio de las pasiones para alcanzar el equilibrio y la tranquilidad del alma.

Se cierra aquí la aportación de los denominados conciliadores, y, aunque resulte contradictorio, en nombre de la ciencia experimental, reducir la filosofía a un estudio más bien físico de la naturaleza, dos cosas quedan de manifiesto, para Ellacuría, tras el estudio de los presocráticos:

a) Desde los albores de la filosofía es la realidad y la observación de lo real lo que mejor parece posibilitar al ser humano para arrancar al mundo su ser y su verdad.

b) Con las distintas filosofías de los presocráticos, la filosofía que se ha ido gestando está más cerca de la realidad y de la verdad de la realidad.

c) Siguiendo los primeros pasos y el pensamiento de los presocráticos se está más cerca de que prenda y despierte en la persona humana la inquietud por la Filosofía.

En general, la máxima aportación presocrática gira en torno a Heráclito y Parménides, iniciadores de una cierta ontología, que puede sintetizarse, según Ellacuría, en lo siguiente:

1. El horizonte en que se desarrolla la problemática del pensamiento filosófico s la naturaleza.

2. Se entiende por naturaleza (fisis) aquel primer y único principio, génesis y origen del que proceden todas las cosas y que las constituye.

3. La cosas tienen una realidad participada de la naturaleza y tienen tanta realidad cuanta sea su participación. 
4. La naturaleza se concibe como un principio activo que proporciona a todas las cosas un elemento común y esencial que es el estar siendo.

5. Heráclito caracteriza ese estar siendo como el devenir; Parménides por el ser idéntico e inmutable.

6. El denominado "ser", Heráclito lo concretiza —-sensibilizándoloen el fuego; Parménides (¿simbolizándolo?) en una esfera maciza. Fuego y ser- esfera son los correlatos reales y sensibles de la idea de naturaleza.

7. La pregunta ya no gira, en Heráclito y Parménides, en torno al principio primero de las cosas sino en torno a la nota esencial y constitutiva de ese principio y de las cosas.

8. Las respuestas divergentes de Parménides y Heráclito abren dos direcciones fundamentales de la filosofía: el ser inmutable y el ser en movimiento.

9. Parménides facilita una evolución del pensamiento hacia la ontología. Heráclito introduce en el ser el concepto de tiempo e historia.

En 1974, en los meses de marzo a junio, Ellacuría impartiría un curso de Introducción a la Filosofía e indicaría como propósito del mismo indagar la idea de la filosofía en la Historia de la Filosofía, con el fin de ver en qué consiste ese típico modo de conocer que es el filosofar y el singular tipo de ciencia que es la Filosofía. En ese curso, volvería sobre "el despertar de la Filosofía: de Tales a Demócrito" y abordaría, además, a Sócrates y los sofistas, a Platón y su idea de la Filosofía, La Filosofía como ética en el epicureismo y el estoicismo, a Aristóteles y su idea de la Filosofía, y a Santo Tomás y su idea de Filosofía.

Pero, en esos mismos meses de marzo a junio de 1974, impartiría también un curso de Metafísica, a modo de recuperación histórica de la Metafísica, en el que abordaría el planteamiento aristotélico; el horizonte de la nihilidad en la metafísica tomista, por influjo del cristianismo, y el sentido de creación; la salida de la incertidumbre en Descartes y la subjetividad como vía de acceso a la realidad; el tema de lo trascendental en Kant y las posibilidades de la metafísica más allá de la crítica metafísica; la razón y el absoluto en la dialéctica de Hegel, así como la Fenomenología del Espíritu; la doble vía de la metafísica mar- 
xista: el antiidealismo y el anticreacionismo como primera vía en el materialismo dialéctico, y la novedad metafísica del materialismo histórico; la metafísica de Comte o la sociología como metafísica de la historia; Bergson y su metafísica de la intuición; y la contraposición sucesiva de Dilthey, Husserl y Heidegger (anclado en la ontología).

En todo este recorrido, de recuperación histórica de la metafísica, parece responder a la inquietud que le llevó al encuentro con Zubiri (de 1961 a 1963): aportar una metafísica nueva, pues una nueva concepción de la esencia y de la realidad da una magnífica base para una consideración existencial del ser humano, en la doble vertiente del hombre como naturaleza y como historia ${ }^{42}$.

En este punto, en cuanto al horizonte de la naturaleza de los presocráticos, parece haber una clara coincidencia entre Zubiri y Ellacuría. Respecto de las cosas y su ser, la metafísica no queda fundada en la ontología sino justo lo contrario: el ser se funda en la realidad; la metafísica es la ciencia de la realidad en cuanto tal. Bastaría a este respecto leer el prólogo de $\mathrm{X}$ a la traducción inglesa de $N H D$ (de 1980) y su referencia a Sobre la esencia (de 1962): sólo existe lo real siendo (realitas in essendo). Pero ya anteriormente, en junio de 1958, Ellacuría, ante las reflexiones del padre Santiago Ramírez sobre $L a$ filosofia de Ortega y Gasset, dice, entre otras cosas lo siguiente:

"Cuando él mismo confiesa — sin mucho dolor_ que para entender el orteguismo se requeriría "una óptica vital con perspectivas vitales: cosa nada fácil, dada nuestra innata propensión a usar de la óptica racionalista, extravital", creo que está apuntando muy hondo, aunque él no lo diga con tal ánimo. Habiendo percibido bien que Ortega no demuestra dialécticamente y por silogismos sus proposiciones, sino que, más bien, procura colocarnos ante la realidad misma para que seamos nosotros mismos quienes captemos su ser y su verdad como único modo de captar contenidos vivos que inciten nuestra vitalidad dormida ...Tal vez, pues, no resulte infundada la afirmación de que no ha sido adecuada la actitud fundamental con que Ramírez se ha acercado a Ortega. Y cuando tal actitud flaquea, los resultados deben ser aleatorios" ${ }^{4.3}$.

En las lecciones sobre "El despertar de la filosofía", le interesa a $E$ transmitir que lo principal no es aprender filosofía sino aprender a filosofar. Por eso trata de concretar siempre el problema al que se enfrentan los primeros filósofos y suscitar una auténtica actitud filo-

\section{0}


sófica. Y, frente a la concepción eclesiástica de que la Filosofía sea sierva de la Teología, escribió en septiembre de 1966, en Bilbao:

"La Filosofía, que ha hecho mucho daño a la Teología cuando se ha pretendido que se convierta en su sierva, puede prestarle grandes servicios cuando como ciencia respete su propio ser autónomo, ahondando en los problemas de la realidad, ahondando en el ser del hombre y enriqueciendo a ésta más que con nuevas ideas, con nuevas formas y potencias de pensar" ${ }^{\prime+4}$.

No es, pues, de extrañar que, con el tiempo, llegase a proponer como objeto de la Filosofía no sólo la realidad sino la realidad histórica y la realidad histórica en cuanto tal, puesto que, desde la perspectiva del ser humano, animal de realidades, la dimensión histórica de la realidad es esencial en esa realitas in essendo (de lo real siendo), realidad estructuralmente compleja y dinámica.

\section{Finalidad ética de la filosofía. filosofía y política}

Sobre la relación entre la Filosofía y la Política, señala Ellacuría, al hablar de Anaxágoras !o siguiente: "Es significativo que tanto él como Sócrates, dedicados exclusivamente al pensamiento y al enjuiciamiento de los contemporáneos y su situación, sin entrometerse en la política ni en ocupación alguna lucrativa, acabaron acusados y condenados por quienes se consideraban instauradores de la democracia; no obstante, Anaxágoras no alcanzó la limpidez y la firmeza, la religiosidad y la seriedad, consecuentes hasta el heroísmo, de Sócrates"

Sócrates a los 70 años (en el año 399) fue condenado por su intervención filosófica en la polis, porque le habían acusado según lo que parecía y no según lo que era. Le habían acusado porque, como hombre sabio (sofos), indagaba en los fenómenos celestes e investigaba todo lo que hay en las profundidades de la tierra, y porque se suponía que los que se dedican a eso no creían en los dioses. Fra también acusado de sofista, es decir, de transformar los argumentos débiles en fuertes $\mathrm{y}$, viceversa, los supuestos argumentos fuertes en débiles. Además, era acusado de corromper a los jóvenes y enseñarles el arte de interrogar a los que se consideraban sabios sin serlo, desenmascarando su falacia. Y, finalmente, era acusado de no creer en los dioses en los que creía la ciudad y de sustituirlos por divinidades nuevas (daimonia).

Sócrates y los presocráticos, desde Ignacio Ellacuria 
En realidad, a Sócrates le habían acusado y condenado porque había indispuesto y molestado con, su talante y su modo de dialogar, a quienes se consideraban sabios sin serlo, fueran políticos, poetas o comediantes.

Sócrates, en el año 406 a. C., gracias al sistema democrático del sorteo pasó a formar parte del Consejo Ateniense de los Quinientos. En dicho Consejo manifestó una gran libertad de criterio tanto respecto de los demócratas como de los oligarcas. En efecto, era miembro de la Comisión Pritana cuando, en contra de la Comisión, la Asamblea Popular exigió la condena a muerte de los generales que habían combatido en la batalla naval de Arginusas. Sócrates se negó a apoyar aquella voluntad popular. Posteriormente, desobedeció a los Treinta Tiranos de Grecia (Los Oligarcas) cuando le ordenaron prender a León de Salamina para conducirlo a la muerte. En el 403 se reconciliaron los bandos opuestos y los demócratas volvieron al poder. Atenas se vio debilitada frente a Esparta y el poder de los persas. Los nuevos gobernantes y el pueblo ateniense consideraban a los sofistas como causantes de los males acaecidos a la Ciudad. Y, aun no siéndolo, a Sócrates se le calificó como sofista.

Una vez condenado Sócrates, Critón, amigo de la misma edad y del mismo demo que Sócrates, considerando injusta la sentencia, trata de que se evada. Pero Sócrates rebate todos los argumentos que tratan de persuadirle para que conserve su vida. De Sócrates, que no es el primer filósofo, pero sí en quien descubrimos la exigencia vital del filosofar, dice Ellacuría:

"No podía ni sabía hacer otra cosa. Un espíritu interior lo impulsaba. Tenía vocación. Filosofaba por vocación. Hasta tal punto que sostenía que una vida sin filosofar no merecía la pena, y por ello, cuando le pidieron que dejara de filosofar para poder seguir viviendo, prefirió tomar la cicuta de su condena a muerte. No quiso ni abandonar la ciudad, ni dejar de filosofar, las dos condiciones que le ponían para salvar su vida: eran dos cosas indisolubles para él; filosofaba en su ciudad y para su ciudad, vivía para filosofar, pues filosofar era su vida" +6

La ciencia de Sócrates, tal como queda recogido en el libro de Platón Defensa de Sócrates, era una ciencia humana (anthropine sofía) y no como la de los otros (políticos, jueces, poetas, adivinos...) una ciencia más que humana. Basándose en este libro de Platón, Ellacuría, 
en 1973, estructura un curso de Filosofía Política, titulado "Antropología Política”. En la segunda parte subraya la triple dimensión del ser humano: individual, social e histórica, y lleva por título: "antropología política y realidad personal del hombre". La primera parte: "Filosofía y Política" aborda el ejemplo de Sócrates y la relación entre el filósofo y la polis, para establecer luego la relación entre Filosofía y Política, así como las tres dimensiones de la Filosofía.

En el establecimiento de las tres dimensiones de la Filosofía, E se atiene a las indicadas por Zubiri: el saber acerca de las cosas, el saber rector del mundo y la filosofía como forma de vida ${ }^{47}$.

¿En qué sentido el oráculo de Delfos dijo que no había nadie más sabio que Sócrates? ¿ Cómo puede ser el más sabio quien tiene conciencia de no serlo ni grande ni pequeño?

En la "Defensa de Sócrates" consta, tal como lo indica Ellacuría en el curso de $1972^{48}$ que fue a buscar hombres que pasaban por sabios, interrogando a cada uno de ellos:

1) Fue a dialogar, ante todo, con un político (tis ton politikon), y al demostrarle que no sabía, que no era sabio, se ganó su enemistad,

2) Comprobó que los poetas, al igual que los profetas y los adivinos dicen cosas bellas, pero no saben lo que dicen.

3) Comprobó, además, que los artesanos (jeirotechnas), porque sabían bien su oficio, y en ese sentido dominaban un saber hacer que él desconocía, creían saberlo todo bien.

En consecuencia, concluyó Sócrates: Soy más sabio que todos ellos en cuanto no creo saber lo que no sé (oti a me oida oude oiomai eidenai). Es por dar la razón al dios que yo demuestro a la gente su ignorancia y me gano su enemistad.

Sócrates adoptó tal misión porque su preocupación era hacer lo que es justo y lo que su vocación divina le exigía. E transcribe sintéticamente lo siguiente en boca de Sócrates:

- No podía desertar de la tarea que un dios me había encomendado, la tarea de vivir filosofando (filosofonta me dein dsen) y de escructurarme a mí mismo y a los otros (exetadsonta emauton kai tous allous), 
- y aunque esto me cueste la muerte, no cesaré, porque yo obedeceré antes a los dioses que a vosotros (peisomai de mallon to theo $e$ $y \min$ ), y son los dioses los que me obligan a decir a los atenienses que se preocupen más de la razón, de la verdad y del alma, que de la fortuna, la reputación y los honores,

- mi tarea es decirles que la fortuna no hace la virtud (ouk ek jrematon arete gignetai) sino la virtud hace las riquezas (all ex aretes jremata) y todo lo que es ventajoso tanto a los particulares como al estado,

- soy un hombre dado por la divinidad a la ciudad; preguntaros si es posible despreciar, como yo, todos los intereses personales y soportar las consecuencias de este desprecio durante años, para ocuparme únicamente de vds. A fin de que sean mejores. Y como prueba de esto sólo tengo un testigo: mi pobreza (ego parejomai ton martyra os alethe lego, ten penian).

- Sin embargo, me he abstenido de entrar en los asuntos públicos:

- si me hubiera dedicado a la política (ta politika pragmata), hace tiempo que estaría muerto,

- no hay quien pueda evitar el sucumbir por poco que se oponga generosamente a los políticos o a la multitud, si es que se dedica a impedir en su ciudad las injusticias e ilegalidades (adika kay paranoma),

- si alguien quiere combatir verdaderamente por la justicia y quiere sobrevivir algún tiempo es mejor que lo haga como particular y no como político (idioteuein, alla me demosteuein),

- una vez tuve un puesto público, como miembro del Consejo, y preferí peligrar con la ley y la justicia más bien que asociarme con los demás en su voluntad de injusticia por temor a la prisión y a la muerte,

- cuando quisieron asociarme a medidas injustas para que fueran muchos los injustos, también lo rehusé en tiempo de la Oligarquía.

Coherente con lo expuesto, Sócrates, en su defensa, dice fundamentalmente lo que sigue:

1) "Hombres, aquel de vosotros que, como Sócrates, ha caído en la cuenta de que no vale nada en verdad en lo tocante a sabiduría, es el más sabio". Esta es la razón por la cual me dedico todavía hoy a andar 
de acá para allá buscando e inquiriendo de acuerdo con las palabras del dios en las personas de todos los que imagino sabios, tanto si se trata de atenienses como de extranjeros, y al parecerme que no lo son, trato de demostrar esto para corroborar lo que el dios ha dicho. Esa tarea ha sido la que ha motivado que no haya tenido tiempo de cumplir ningún cometido político digno de mención, ni de ocuparme de mis intereses particulares; lejos de eso, vivo en una extrema pobreza...

2) Vergonzosa habría sido mi conducta, atenienses, si yo, que permanecía en el puesto que me asignaron mis jefes y corrí el riesgo de morir, como cualquier otro, obediente a aquellos a quienes vosotros elegisteis para mandarme - ello tuvo lugar en Potidea, Anfípolis y Delio-, cuando el Dios me ordenó, según creí y deduje, que viviese dedicado a la filosofía y examinándome a mí mismo y a los demás, hubiese abandonado mi puesto por temor a la muerte o a otra cosa cualquiera...

3) Si, con relación a esto, me dijeráis: "te absolvemos, pero con esta condición: con la condición de que dejes esos diálogos examinatorios y ese filosofar..."

4) Pues bien, ... yo os respondería: "Agradezco vuestras palabras y os estimo, atenienses, pero obedeceré al dios antes que a vosotros y, mientras tenga aliento y pueda, no cesaré de filosofar, de exhortaros y de hacer demostraciones a todo aquel de vosotros con quien tope con mi modo de hablar acostumbrado", y así, seguiré diciendo: "Hombre de Atenas, la ciudad de más importancia y renombre en lo que atañe a sabiduría y poder, ino te avergüenzas de afanarte por aumentar tus riquezas todo lo posible, así como tu fama y honores, y, en cambio, no cuidarte ni inquietarte por la sabiduría y la verdad, y porque tu alma sea la mejor posible?

5) Así, pues, también vosotros, ioh jueces! Debéis tener buenas esperanzas ante la muerte y pensar que hay una cosa cierta, y es que al hombre bueno no alcanza ningún daño, ni en la vida ni en la muerte, y que sus asuntos no son descuidados por los dioses ${ }^{49}$

Lo que Sócrates aporta primariamente no es, pues, un estricto saber político sino las condiciones éticas para un hacer político justo. Por ello, centra su pensar filosófico en lo que el hombre es en realidad y en lo que debe ser el ciudadano y la ciudad. Su modo de intervención no es estrictamente propio de un político, puesto que no quiere 
ocupar ninguno de los cargos políticos. Su intervención es propia del filósofo: quiere despertar la conciencia del individuo, del pueblo y de los gobernantes. La conciencia tiene en Sócrates una clara dimensión de saber pero también una dimensión de voluntad, de querer hacer lo justo. Pero es precisamente este querer despertar la conciencia de la ignorancia y de la injusticia la que provocará la enemistad y la persecución.

¿Acaso no es la referencia a Sócrates preludio de la propia vida y muerte de Ignacio Ellacuría? En la mirada retrospectiva sobre el objeto del saber, en los albores de la Filosofía, descubrimos de la mano de Ellacuría: la realidad (en el horizonte de la Naturaleza), y la doble exigencia de la observación directa de las cosas y de la visión global de las mismas; el sentido histórico del devenir de la realidad, en lo que atañe a la realidad del ser humano; y la finalidad ética del quehacer filosófico, metafísica de transformación, de implicaciones sociales y políticas.

\section{Referencias bibliográficas de interés}

\section{A) En Ignacio Ellacuría}

- Ellacuría, I.: "El despertar de la Filosofía", en EF, T. I, pp. 47-74 (Primera parte: de Tales a Parménides) y pp. 74-107 (Segunda parte: de Empédocles a Demócrito) [años 1956 y 1958, respectivamente]. 215-222.

: "Santo Tomás, hombre de su siglo" (1958), en EF, T. I, pp. : "Posibilidad y modo de aproximación entre la filosofía escolástica y la filosofía vitalista moderna (Reflexiones ante el libro de Ramírez: La filosofia de Ortega y Gasset), T. I, pp. 223-250 (año 1958).

: "Tomás de Aquino, intelectual católico" (1960), en EF, T.I, pp. 329-336.

387-395.

: "El tomismo, ¿es un humanismo?" (1961), en $E F$, T. I, pp. 

: "Filosofía en Centroamérica (a propósito de un libro reciente de Peccorini: El ser y los seres según Santo Tomás de Aquino), en $E F$, T. I, pp. 397-409 (año 1961).

: "Fundamentación de la metafísica ( a propósito del libro de Coreth: Metafísica. Una fundamentación metódico-sistemática)", en EF, T. I, pp. 589-592 (año 1965).

: "Verum est declarativum aut manifestativum esse. Sobre una cita de Santo Tomás", en EF, T. I, pp. 593-596.

pp. 365-444. : "La idea de filosofía en Xavier Zubiri"(1970), en $E F$, T. II, : “Filosofía y política" (1972), en EP, T. I, pp. 47-61. : "Filososfía, ¿para qué? (1976), en EF, T. III, pp. 115-131.

B) EN OTROS AUTORFS

- Aristóteles: Física, Editorial Gredos, Madrid 1998 (primera reimpresión; la primera edición es de 1995).

- ____: Metafísica, Editorial Gredos, Madrid 1998 (primera reimpresión; la primera edición es de 1994).

-

: Ética Nicomáquea. Ética Eudemia, Editorial Gredos, Madrid 1988 (primera reimpresión; la primera edición es de 1985).

- _ _ _ Política, Editorial Gredos, Madrid 1988.

- Cubells, Fernando: Los filósofos presocráticos, Anales del Seminario, Valencia, 1965.

- Ferrer, Francisco; Montero, Fernando y otros: La Filosofía Presocrática, Universidad de Valencia, Jávea (Valencia) 1978.

- HEGEL: "El comienzo de la Historia de la Filosofía", en Introducción a la Historia de la Filosofía, Aguilar, Madrid 1989, pp. 256276.

: Lecciones sobre Historia de la Filosofía, (3 vol.), Fondo de Cultura Económica, México, 1996 (sexta reimpresión; la primera edición en español es de 1955).

- Kirk, G. S.; Raven, J. E.; y Scofield, M: Los filósofos presocráticos, Edit. Gredos, Madrid 1987 (la primera edición es de 1970). 
- Martín Gómez, Manuel: La audacia del saber, Editora Andaluza Hergué, Huelva 2000.

- PLATÓN: "Defensa de Sócrates", en Obras completas, Aguilar, Madrid 1990 (segunda edición, novena reimpresión), pp. 197-218.

- __ _. "Critón o del deber", en ibid., pp. 219-232.

- ___ __ "Fedón o del Alma", en ibid., pp. 610-652.

- ___ : "Teeteto o de la Ciencia", en ibid., pp. 885-941.

- ___ "Parménides o de las idéas", en ibid., pp.956-990

- ___ "El "El sofista o del ser", en ibid., pp. 999-1043.

- Uña Juárez, Agustín: Asi nació la Filosofía (Sobre el texto de Aristóteles, Metafísica I, 3 en torno a Tales de Mileto), Universidad Complutense de Madrid, Madrid 1999.

- Zubiri: "Realidad, Ciencia, Filosofía", en NHD, Alianza Editorial, Madrid 1994 (10ª ed.), pp. 25-156.

265. : "Sócrates y la sabiduría griega" (1940), en op. cit., pp.186-

- _ Los problemas fundamentales de la Metafísica, Alianza Editorial, Madrid 1994.

NOTAS

1. Cfr. Ellacuría, I.: "El despertar de la Filosofía", en EF, T. I, p. 50. Conviene subrayar, de inmediato, que Ellacuría, al tiempo que impartía Ontología c Historia de la Filosofía, había analizado la filosofía y la persona de Josć Ortega y Gasset, publicando en 1956, en la revista ECA: "Ortega y Gasset: hombre de nucstro ayer" (en mayo); "Ortega y Gasset, desde dentro" (en junio); y "¿Quién es Ortega y Gasset? (en noviembre). Además, del estudio interno de sus lecciones sobre los presocráticos, se deduce claramente su conocimiento de Platón, de Aristóteles y de Hegel, fundamentalmente, así como del libro de Zubiri: Naturaleza, Historia, Dios, del que cita "El acontecer humano: Grecia y la pervivencia del pasado filosófico" (de 1942) y "Sócrates y la sabiduría griega" (1940). En el estudio de los presocráticos se apoya en los manuales de Historia de la Filosofía de Fraile, publicado en la BAC, y en el de Johannes Hirschberger, publicado en la cditorial Herder, pero también recurre a la primera parte de las Lecciones sobre la Historia de la Filosofía de Hegel, sobre "La Filosofía Griega". Finalmente, conviene significar que, precisamente, en 1958, la visita de Ellacuría a la Exposición Universal de Brusclas (Bélgica) da pic a que nos transmita la visión que él 
tiene sobre el contexto de la época atómica, en que la desmedida importancia que iba adquiriendo el apogeo de la materia y de la técnica (bajo el símbolo del atomium) planteaba un dilema: o la dedicación a la técnica en menoscabo de los valores humanos y espirituales, o el rezagamiento $y$, en consecuencia, el futuro sometimiento a las fuerzas materialistas (ya en 1934 señalaba Zubiri, en torno a "La idea de Naturaleza: la Nueva Física", la consagración de una nueva etapa en la historia del saber físico, en relación con la nueva mecánica del átomo). Más tarde, en 1966, reflexionará Ellacuría sobre aptitud y actitud necesarias para filosofar, a propósito de unos cursos impartidos en Bilbao, y volverá, posteriormente, en repetidas ocasiones, al estu dio de la cosmología griega (en 1970) y a la dialéctica en el mundo griego, especialmente en los presocráticos y en Sócrates, en 1973 y en 1974, en los cursos impartidos en la UCA, de los que existe constancia en los archivos personales (ADE, Cur: 1.3.2.1: Filosofía). Los cursos sobre "Filosofía Política", en la UCA, datan de 1973 (agosto / noviembre), tiempo en el que se publica la Teología Política, aunque ya en 1972 publicara un ensayo sobre Filosofía y Política.

2. En la traducción se transcribe la facilitada por Manuel Martín Gómez, en La audacia del Saber, Editora Andaluza Hergue, Huelva 2000, p. 13.

3. Ibid., pp. 55-56

4. Ibid., p. 56

5. Cfr. Cubells, Fernando: Los filósofos presocráticos, Anales del Seminario de Valencia, Valencia 1965, pp. 65-67.

6. Aristóteles: Metafisica, Editorial Gredos, Madrid 1998 (primera reimpresión), p.89

7. Cfr.: Reale, Giovanni y Antiseri, Dario: Historia del pensamiento filosófico y cientifico. I (Antigüedad y Edad Media), Herder, Barcelona 1995, pp. 45-52

8. Convendría puntualizar que Ellacuría introduce habitualmente el epíteto expresivo "verdadero", referido al ser de las cosas y también a la realidad, para designar su esencia, así como su virtualidad o potencialidad, distanciándose, consecuentemente, del pensamiento ontológico (sobre el ser en cuanto ser) en favor de la metafísica que trata no de la realidad en cuanto tal, conforme al pensamiento de Zubiri. Respecto del concepto "Ciencia", aplicado a la Filosofía, se entiende tan sólo como aquella teoría que tiene como base, aunque mediata, la experiencia, pero no la verificación empírica, propia de la Ciencia en sentido estricto.

9. Cfr. Zubiri, Xavier: "Sócrates y la sabiduría griega", en NHD, Alianza Editorial, Madrid 1994 (10.7 ed.), pp. 210-218 (sobre la sabiduría como visión del ser).

10. Ellacuria, I.: "El despertar de la lilosofía", en $E F, \mathrm{~T}$ I., op. cit., p.59. No se olvide lo dicho sobre el epiteto expresivo "verdadero/a".

11. Cfr. Hegel, G. W. F.: "La Filosofía de Heráclito", en Leccones sobre Historia de la Filosofía, Fondo de Cultura Económica, México 1955, pp. 258-276.

12. En esta comprensión de Heráclito, Ellacuría sigue la exposición de Zubiri sobre la sabiduría como visión del ser, expuesta en "Sócrates y la sabiduría griega", en NHD, pp. 210-218, quien considera anacrónico pretender que Parménides y Heráclito hayan creado un concepto del ser. Para Pármenides, su presunto "ser" es una esfera maciza; para Heráclito, el luego. Por lo que la interpretación de los fragmentos debe centrarse no sobre el ser ni sobre el ente en general sino sobre la Naturaleza, principio y sustento de todas las cosas.

13. Ellacuría, I.: "El despertar de la Filosofía", en EF, T I., op. cit., p. 63 
14. Cfr. Cubells, Fernando: Los filósofos presocráticos, Anales del Seminario de Valencia, Valencia 1965, p. 157

15. Cfr. Ibid., pp. 148-150

16. Sobre los textos de Parménides y el esfuerzo de traducción ajustada es conveniente consultar a Conrado Eggers Lan y Victoria E. Juliá en su obra ya clásica Los Filósofos Presocráticos, I, Editorial Gredos, Madrid 1978 (sobre Parménides, ver pp. 401-484).

17. Ellacuría, I.: "El despertar de la Filosofía, en $E F$, T. I., op. cit., p. 70

18. Cfr. Eggers Lan, Conrado: "Parménides", en Los filósofos presocráticos, I., op. cit., p. 413

19. Ellacuría, I.: "El despertar de la Filosofía", en EF, T.I., op. cit., p. 71

20. Ibid., p. 72

21. Cfr. Hegel, G.W.F.: Lecciones sobre Historia de la Filosofia I, op. cit., pp. 241243.

22. Cfr. Ellacuría, Ignacio: "El despertar de la Filosofía", en op. cit., p. 74.

23. Cfr. Ellacuría, Ignacio: "El despertar de la Filosofía", en op. cit., p. 50

24. Cfr. Platón: "Teeteto, o de la Ciencia", en Obras Completas, Aguilar, Madrid 1990 (2.' edición), p. 901.

25. Martín Gómez, Manuel: La audacia del saber, op. cit., pp. 56-57 (cita entresacada del capítulo V: "Verdad, certeza e investigación en Jenófanes de Colofón - 570475 A.C.—“", pp. 55-65).

26. Cfr. Ellacuría, 1.: "El despertar de la Filosofía" (segunda parte: de Empédocles a Demócrito), en op. cit pp. 75-76

27. Cfr. Kirk, G.S., Raven, J.E., Y Schofield, M.: Los filósofos presocráticos. Historia crítica con selección de textos, Editorial Gredos, segunda edición ampliada (la primera en español data de 1970), Madrid 1987, pp. 400-403 (del cap. X: Empédocles de Acragas). Para un estudio más amplio sobre Empédocles puede consultarse a Ernesto La Croce, en Néstor Luis Cordero, Francisco José Olivieri y otros: Los filosofos presocraticos, II, Editorial Gredos, Madrid 1979, pp. 127 294: "Empédocles de Agrigento".

28. Ellacuria, l.: "El despertar de la Filosofía", en op. cit., p. 79.

29. Ibid., p. 79

30. Ibid., p. 81

31. Hegel, G. W. F.: Lecciones sobre la Historia de la Filosofia, I, op. cit., p. 291. De todos modos parece arriesgado extraer distinciones muy racionales de los fragmentos de los presocráticos cuando su contexto era totalmente otro al de Hegel y al nuestro, pues las mismas raíces de todas las cosas, los cuatro elementos, eran también denominados mitológicamente: Zeus resplandeciente (personificación del cielo luminoso, dios supremo de la luz), Hera dadora de vida (que simboliza la unión del cielo con la tierra, es el elemento femenino en la vida del universo), Edoneo (que nos permite respirar el aire de la vida) y Nestis, que con sus lágrimas empapa las fuentes de los mortales.

32. Ellacuría, I.: "El despertar de la Filosofía", en op. cit., pp. 84-87. La transcripción del fragmento de Empédocles, recogido por Aristóteles en la Metafísica, libro IIl, capítulo IV, 1000 b 6-8, lo recoge nuestro autor conforme a la traduc- 
ción de García Bacca, tal cual aparece en la obra de Hegel: Lecciones sobre Historia de la Filosofía, I, op. cit., p. 291. Nosotros hemos modificado la preposición "con" por la preposición "por" (Por la tierra conocemos la Tierra). Más que falsa, la explicación es intrincada.

33. Ibid., p. 88

34. Ibid., p. 91

35. Ibid., p. 94

36. Ibid., p. 95

37. PLATÓN: "Fedón, o del alma", en Obras completas, op. cit., pp. 639-640

38. Cfr. Ellacuría, I.: "El despertar de la Filosofía", en op. cit., p.96

39. El texto del Fedón es transcrito tal cual lo hace Ellacuría en "El despertar de la Filosofía", en EF, T. I., op. cit. p. 103.

40. En la traducción de este texto seguimos a Francisco Ferrer, Fernando Montero y otros, en La Filosofía Presocrática, Universidad de Valencia, Jávea (Valencia), 1978, p. 259.

41. Ellacuría, I.: "El despertar de la Filosofía”, en EF, T. I., op. cit., p. 103.

42. Cfr. "Conversaciones con Zubiri", en EF, T. II., pp. 19-51

43. Cfr. Ellacuría, I.: "Posibilidad y modo de aproximación entre la filosofía escolástica y la filosofía moderna", en $E F$, T. I., op. cit., p. 235.

44. Cfr. Ellacuría, I.: "Introducción a la Filosofía", en EF, T. I., op. cit., p. 623.

45. Ibid., p. 89

46. Cfr. Ellacuría, 1.: "Filosofia, ¿para qué? (1976), en EF, T.III., op. cit., p. 118.

47. El tema, abordado en el prólogo a la primera edición de la Historia de la Filosofía (1941), de Julián Marías, es reproducido en NHD de Zubiri y está datado en diciembre de 1940.

48. Cfr. El curso de Filosofía Política (1972), la parte primera sobre "el ejemplo de Sócrates", en el Archivo Documental, Cursos, 1.3.2.1. Filosofía.

49. Cfr. Platón “Defensa de Sócrates", en Obras completas, op. cit., pp. 205-218 